\title{
Feather mite abundance increases with uropygial gland size and plumage yellowness in Great Tits Parus major
}

\author{
ISMAEL GALVÁN* \& JUAN J. SANZ \\ Departamento de Ecología Evolutiva, Museo Nacional de Ciencias Naturales (CSIC), José Gutiérrez Abascal 2, E-28006 \\ Madrid, Spain
}

\begin{abstract}
Plumicolous feather mites are ectosymbiotic organisms that live on bird feathers. Despite their abundance and prevalence among birds, the ecology of the interaction between these organisms and their hosts is poorly known. As feather mites feed on oil that birds spread from their uropygial gland, it has been hypothesized, but never tested, that the number of feather mites increases with the size of the uropygial gland of their hosts. In this study the number of feather mites is considered with respect to uropygial gland size in a breeding population of Great Tits Parus major in order to test this hypothesis. As predicted, the number of feather mites correlated positively with the uropygial gland size of their hosts, showing for the first time that uropygial gland size can explain the variance in feather mite load among conspecifics. Previous studies relating feather mite load to plumage colour have suggested that feather mites may be parasitic or neutral. To confirm this, the yellowness of breast feathers was also assessed. However, the results ran in the opposite direction to that expected, showing a positive correlation between mite load and plumage yellowness, which suggests that further work is needed to give clear evidence for a specific nature of feather mites. However, Great Tits with higher mite loads had lower hatching and breeding success, which may support the idea that feather mites are parasites, although this effect must be taken with caution because it was only found in males. Age or sex effects were not found on the number of feather mites, and it is proposed that hormonal levels may not be sufficient to explain the variation in feather mite loads. Interestingly, a positive correlation was detected between uropygial gland size and plumage brightness, which could be a novel factor to take into account in studies of plumage colour.
\end{abstract}

Feather mites (suborder Astigmata; superfamilies Analgoidea, Freyanoidea and Pterolichoidea) are symbiotic arthropods that live inside the quills or between the barbs of the feathers of birds, representing the majority of bird-mite associations (Proctor \& Owens 2000). Most studies dealing with these organisms have focused on taxonomic aspects, but little is known about the ecology of the interactions with their hosts. A controversy exists over the nature of these interactions, as some authors have found detrimental effects for their hosts (Thompson et al. 1997, Harper 1999, Pérez-Tris et al. 2002, Figuerola et al. 2003), whereas others have reported a positive relationship (Blanco et al. 1997, Jovani \& Blanco 2000, Blanco \& Frías 2001) or no relationship (Blanco

${ }^{*}$ Corresponding author.

Email: galvan@mncn.csic.es et al. 1999, Dowling et al. 2001b) between mite abundance and host body condition or fitness. However, there seems to be more empirical evidence for a mutualistic or at least commensal nature than for a parasitic nature of feather mites, which is supported by theoretical arguments (Blanco et al. 2001).

Following other authors (e.g. Jovani \& Serrano 2001), the term 'feather mites' is used here following prior ecological rather than systematic studies, thus considering only those mites living on the surface of feathers (i.e. plumicolous mites) and not those living inside the quills or on the skin of birds (Proctor 2003). The mouthparts of these mites are designed for scraping, which makes them unable to feed on solid material, except for that dissolved in oil (Blanco et al. 1997, Proctor \& Owens 2000). Indeed, their main food consists of waxes and fatty acids secreted by the uropygial gland that they lick from the surface 
of the feather barbules, and also scurf, pollen and fungi that adhere to the feather barbs (Proctor 2003). Therefore, it has been suggested that these mites could improve the efficiency of feather preening and host condition by removing old oil and detritus accumulated on feathers, as well as pathogenic micro-organisms associated with these substances, which may decrease feather quality (Blanco et al. 1997, 2001, Jovani \& Blanco 2000). Other ectosymbionts also benefit from the oil secretions of their bird hosts (Saino et al. 1995). Blanco et al. (1997) suggested that the positive relationship between feather mite abundance and body condition in Red-billed Choughs Pyrrhocorax pyrrhocorax could be due to larger volumes of uropygial oil produced by birds in prime condition. A similar interpretation was proposed by Jovani and Blanco (2000) for the positive relationship they found between mite abundance and fat scores in Long-tailed Tits Aegithalos caudatus. Blanco et al. (1999) found higher mite loads on male than on female Linnets Carduelis cannabina, and attributed this to the more abundant secretion of the uropygial gland of males, which may be stimulated by their higher androgen levels. Dowling et al. (2001a) also speculated that the higher mite loads they found on juvenile Seychelles Warblers Acrocephalus sechellensis could be due to larger amounts of uropygial oil produced by these individuals. Finally, Blanco and Frías (2001) suggested that the increase in feather mite abundance observed in Barn Swallows Hirundo rustica during the premigratory period could be due to the high levels of certain hormones produced during this period, which in turn increase the activity of the uropygial gland. However, the question of whether individuals able to secrete more oil from the uropygial gland have higher mite loads has not been explicitly tested. The size of the uropygial gland could reflect this relationship, as birds with larger uropygial glands secrete greater volumes of oil (Elder 1954). Dubinin (1951) was the first to present this hypothesis in the 1950s, but to date no study has related feather mite abundance to uropygial gland size. The first aim of the present study was to search for a possible relationship between feather mite abundance and the size of the uropygial gland in a population of Great Tits Parus major breeding in nestboxes. As feather mites benefit from the oil secretions that birds spread from the uropygial gland, it was predicted that birds with larger glands would harbour more mites in their feathers.

In order to search for possible evidence of a parasitic nature of feather mites, different reproductive parameters were also related to feather mite abundance, as a relationship with breeding performance has never been investigated for feather mites. As both endoparasites (e.g. Merino et al. 2000, Sanz et al. 2001) and ectoparasites (Clayton \& Tompkins 1995) have detrimental effects on the breeding performance of their hosts, a negative effect on reproductive parameters was predicted for those Great Tits with higher mite loads if the parasitic nature of these organisms was significant.

Finally, all the authors who have previously related colour measurements to feather mite abundance or prevalence (Thompson et al. 1997, Blanco et al. 1999, Harper 1999, Figuerola 2000, 2003) have used subjective scoring methods to classify the colours, although Figuerola et al. (2003) did also use quantitative methods for colour measurement. Therefore, the colour of the yellow breast feathers of Great Tits was analysed here by using UV/visible reflectance spectrophotometry in order to search for possible relationships with feather mite abundance after dividing the spectral data into different components by using a principal components analysis (PCA; Cuthill et al. 1999). It is known that plumage coloration is related to body condition in species with carotenoidbased plumages, thus acting as an honest signal (for a review see Senar 2004). The mites that act as parasites negatively affect the body condition of their bird hosts in many ways (Proctor \& Owens 2000), and birds in prime condition (e.g. with brighter plumages) should be signalling their resistance against parasites (Hamilton \& Zuk 1982). As all the authors who have previously searched for a relationship between feather mite abundance and plumage colour have obtained evidence for a parasitic (Thompson et al. 1997, Harper 1999, Figuerola et al. 2003) or neutral (Blanco et al. 1999) bird-mite interaction, a negative or non-significant relationship between feather mite abundance and any component of the plumage colour of Great Tits was predicted in order to confirm these findings.

\section{STUDY AREA AND METHODS}

\section{General field methods}

The study was carried out in May-June 2005 in a deciduous forest of Pyrennean Oak Quercus pyrenaica at $1200 \mathrm{~m}$ above sea-level in Miraflores de la Sierra, Sierra de Guadarrama, central Spain $\left(40^{\circ} 49^{\prime} \mathrm{N}\right.$, $03^{\circ} 46^{\prime} \mathrm{W}$ ). Frequent checks of nestboxes provided data on dates of clutch initiation and clutch size for 
all breeding pairs. On the fourth day after hatching, adults were captured and banded with numbered rings. The adults were weighed with a portable electronic balance to the nearest $0.1 \mathrm{~g}$, their tarsus length was measured to the nearest $0.01 \mathrm{~mm}$ with a digital calliper and their wing chord was measured to the nearest $1 \mathrm{~mm}$ with a rule as a measure of body size (Svensson 1992, Gosler et al. 1998). The birds were classified as of one or more years according to plumage characteristics (Jenni \& Winkler 1994). In total, 43 Great Tits $(20$ males and 23 females, representing 27 adults, 15 yearlings and one individual of unknown age) belonging to 24 breeding pairs were captured and examined for feather mites. One female laid a second clutch, but only its first clutch was considered in the analyses. Only one female was moulting flight feathers during the study period, but no mites were detected in this bird.

Length of incubation was defined as the number of days between completion of the clutch and first signs of hatching. Nestlings were ringed on day 14 after hatching (hatching date $=$ day 0 ) and weighed in the same way as adults. Broods were visited again on subsequent days to establish numbers of fledged and dead young. Hatching success (proportion of eggs hatched), fledging success (proportion of hatchlings that resulted in fledged young), breeding success (proportion of eggs that resulted in fledged young) and fledgling mass were considered as partial measures of reproductive success.

Although mites of several genera (Uniscutalges, Proctophyllodes, Strelkoviacarus, Pteronyssoides, Monojoubertia, Analges and Microlichus) have been collected from Great Tits, the most commonly recorded mite associated with wing feathers is Proctophyllodes stylifer (Buchholz) (Cerny 1964, 1971, Atyeo \& Braasch 1966, Jablonska 1986, Behnke et al. 1995, Nattress 1995, Mironov 1996, 1997), which is thus the most probable mite species recorded here. Following other authors (e.g. Jovani \& Serrano 2001), feather mites were counted by extending and exposing the wings of the birds to daylight. This method is as accurate as other techniques that use the removal of mites, such as dust-ruffling (Dowling et al. 2001 a, 2001b). Only the right wing was used, as the numbers and distributions of feather mites on both wings of the same bird are highly correlated (Jovani \& Serrano 2004). The type of feather harbouring mites (primaries, secondaries or tertials) was also recorded, as feather mites are not distributed randomly among wing feathers, but respond to conditions that vary between feathers (Jovani \&
Serrano 2001, 2004). In the analyses the total number of mites on each feather type was divided by the number of feathers in the corresponding group (ten primaries, six secondaries and three tertials; Jenni \& Winkler 1994) to estimate the mite load per feather. Searches for mites were made on flight feathers because mite abundance tends to be high in this feather type (Jovani \& Blanco 2000).

The uropygial gland of the Great Tits was inspected visually by soaking the surrounding feathers with moist cotton. This heart-shaped holocrine gland is located in the rump, embedded beneath the skin just dorsal to the levator muscle of the tail (Elder 1954), and its relatively large size makes it easy to measure. In the Great Tit the gland has two lobes and only one opening to the outside through a nipple structure. Three measurements were taken to estimate the size of the uropygial gland: maximum width, maximum length and 'height'. A digital calliper was used to take these measurements to the nearest $0.01 \mathrm{~mm}$. Width measures were taken from the left lobe of the gland, while length was considered as the maximum distance from the end of one lobe to the other. The 'height' of the gland was expressed as the distance between the base of the lobes and the end of the nipple. These measurements were multiplied to obtain an estimate of the volume of the gland. Although a rough approximation to real size, this measure should be adequate for comparative purposes. Daily production of oil is regulated by hormone levels (Jacob \& Ziswiler 1982). Thus daily variations in preening activity of birds and, as a consequence, variations in gland size are likely to occur. Perhaps in response to this, and to abiotic factors, the location of feather mites in a bird's feathers can also vary during the day (Dubinin 1951, Wiles et al. 2000). Because this could affect the observer's ability to see the mites, the hour of capture was also recorded and considered in the analyses, but this did not affect the size of the uropygial gland (Pearson's correlation test: $r=0.061$, $n=43, P=0.698)$.

\section{Spectrophotometric analyses}

For the spectral analyses of the yellow breast, 17 Great Tits (eight males and nine females from 11 breeding pairs) were used. Data were collected in the field using an Ocean Optics USB2000 spectrophotometer (range 250-800 nm) with UV (deuterium) and visible (tungsten halogen) lamps and a bifurcated 400 micrometer fibre-optic probe (Dunedin, FL, USA). The fibre-optic probe provided both illumination 
and obtained light reflected from the sample, providing a reading area of $c .1 \mathrm{~mm}^{2}$. The spectrometer measured reflectance in $0.36-\mathrm{nm}$ increments. All measurements were relative to a white 'Spectralon' tablet (WS-1-SS, Ocean Optics), and one reference measurement was made for each bird. The spectral curves were generated by using OOIBase software. Similar to the method of Mennill et al. (2003), three readings were obtained on different points of the upper part of the right side of the yellow breast of Great Tits moving the probe by at least $5 \mathrm{~mm}$ before taking each new reading, but always following the same order (from top to bottom). These three measures were averaged to obtain a spectrum for each bird. However, due to time constraints the three measures could only be taken for eight birds. For the remainder of the birds only one measure could be used. Curves were arranged by calculating the median of the percentage reflectance in $30-\mathrm{nm}$ intervals beginning at $320 \mathrm{~nm}$ and ending at $700 \mathrm{~nm}$ to cover the full spectral range that can be detected by birds (Cuthill et al. 2000).

\section{Statistical analysis}

The spectral data set was analysed by performing a PCA (see, for example, Hunt et al. 1998, Cuthill et al. 1999, Cherry \& Bennett 2001, Mennill et al. 2003, Moreno et al. 2005). This analysis typically summarizes all the spectral data in two or three statistically independent, orthogonal axes. The first segregated component usually explains $80-90 \%$ of the total variance and is related to reflectance in all regions of the spectrum, thus reflecting achromatic brightness, whereas the other two components correspond to variation in the shape of the spectral curve (hue and chroma; e.g. Hunt et al. 1998, Cuthill et al. 1999, Cherry \& Bennett 2001, Mennill et al. 2003, Moreno et al. 2005). Accordingly, in this case the PCA produced two axes explaining $97.6 \%$ of the total spectral variance. The first component $(\mathrm{PCl})$, which explained $82.8 \%$ of the variance, has high and negative factor loadings across all the spectral regions, and thus it can be considered a measure of achromatic brightness. Numerical values of PCl scores actually represent the opposite of brightness (darkness), with higher values denoting darker feathers. The other component is curvilinear, thus explaining chromatic variation. PC2 accounted for $14.8 \%$ of the variance in the original spectra and was strongly, positively, related to reflectance in UV-blue wavelengths and negatively to yellow-red reflectance. Thus, more positive values of $\mathrm{PC} 2$ denote a tendency towards UV-blue reflectance, whereas more negative values of the axis reflect yellower-redder colorations. It must be noted here that, although the breast of the Great Tit is perceived as yellow by humans, the perception of colour depends on the properties of the nervous system of the receivers, and thus the colour perception mechanisms of birds differ from those of humans (Bennett et al. 1994). This is why the negative side of PC2 includes wavelengths corresponding not only to visible yellow but also to red. The mean spectral data for the 17 birds in which plumage colour was measured are shown in Figure 1, where a peak in the UV portion of the spectra, above the visible range in the case of males, can be observed. Similar peaks have been found in the yellow plumage of other species (Hunt et al. 1998, Johnsen et al. 2003, Mays et al. 2004, Shawkey \& Hill 2005), but it had not been described before in the Great Tit.

Uropygial gland size was also analysed in relation to $\mathrm{PCl}$ scores because it has been suggested that feathers coated with more uropygial oil would look brighter (Andersson \& Amundsen 1996, Blanco et al. 1999).

The total number of feather mites was +1 logtransformed in order to achieve normality. However, the number of mites on each type of feather did not follow a normal distribution even after transformation, and thus a Friedman's test was used to search for differences in mite load between feather types. Uropygial gland size was always included in the analyses by using the residuals obtained when it was regressed against body size (Pearson's correlation test: $r=-0.105, n=43, P=0.503$ ). The effect of hour of capture on the relationship between mite abundance and uropygial gland size was investigated using a multiple regression model with the number of feather mites as a dependent variable. Other multivariate models could not be performed due to problems with sample size or to the impossibility of obtaining significant models, so Pearson correlations, Student's $t$-tests and one-way ANOVAs were used instead. Spearman's rank correlation tests were used when sample size was too low $(n<10)$. The birds which did not harbour feather mites were always included in the analyses, except when searching for differences in mite load between feather types. Clutch size and fledging success were not normally distributed even after transformation, and thus Spearman's rank correlation tests were also used to relate these variables to the number of feather mites. Further reproductive parameters, though used as percentages, were not transformed because normality 


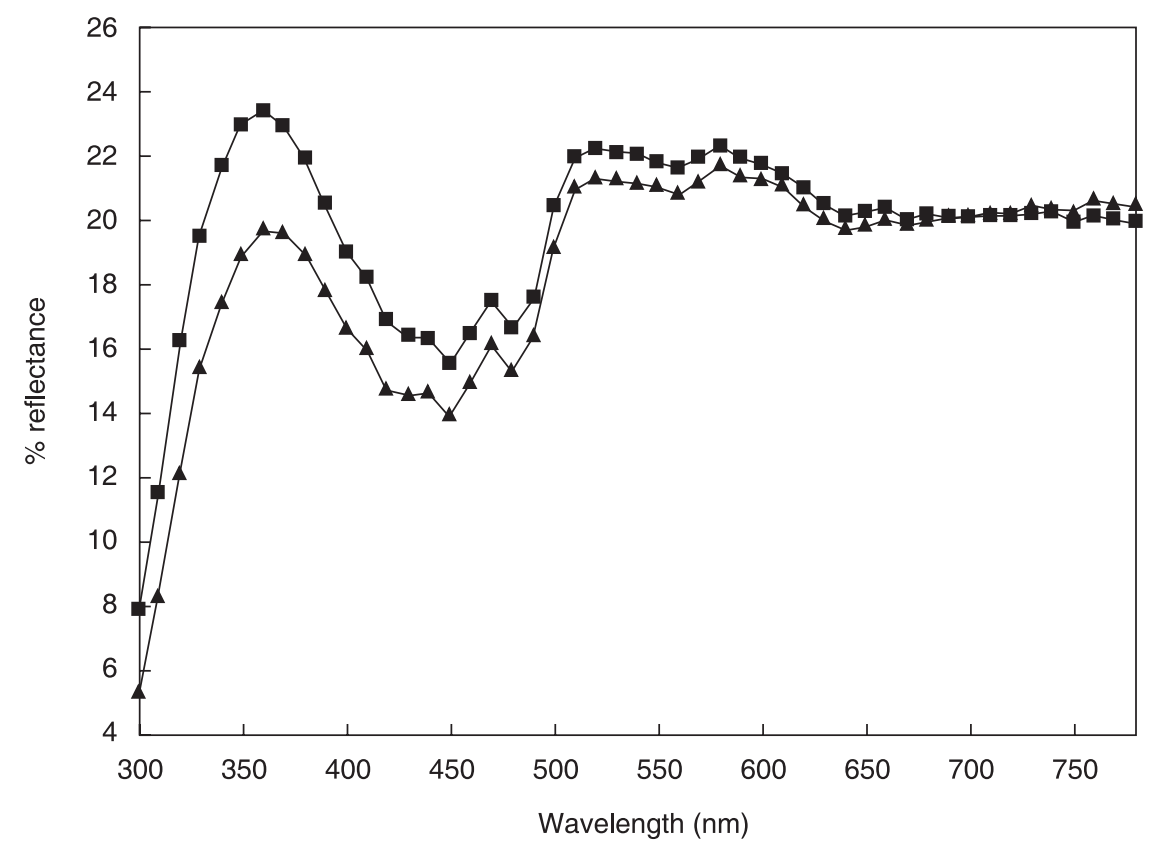

Figure 1. Spectral reflectance of the yellow breast of male (squares) and female (triangles) Great Tits, showing a peak in the UV portion of the spectra. Data are provided in 10-nm intervals. Error bars are omitted for clarity.

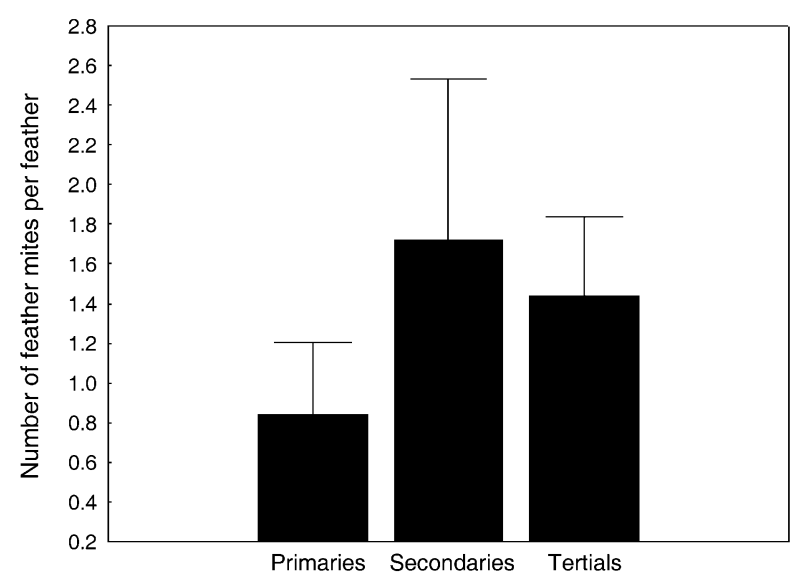

Figure 2. Distribution of feather mites in the different wing feathers (mean $+\mathrm{se}$ ), indicating that the majority of mites are located on secondary feathers.

assumptions were fulfilled, and thus Pearson's correlations were used. Means are expressed \pm 1 sd. All statistical analyses were two-tailed.

\section{RESULTS}

Mite load ranged from one to 170 (mean: $15.0 \pm$ $35.7)$, and prevalence was $65.1 \%(n=43)$. The birds harboured a total of 645 feather mites. There were significant differences in mite abundance between

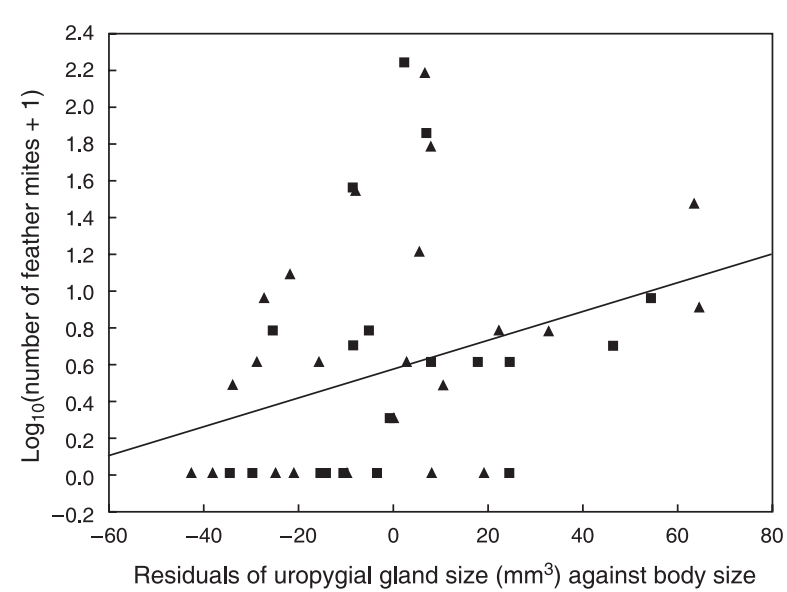

Figure 3. Relationship between the number of feather mites harboured by male (squares) and female (triangles) Great Tits and the size of their uropygial glands.

the different types of wing feathers (Friedman's test: $\left.\left(\chi_{r}^{2}\right)_{2}=7.90, n=28, P<0.019\right)$, with a majority of mites located on secondary feathers (Fig. 2).

\section{Uropygial gland size}

As predicted, the number of feather mites was positively related to the size of the uropygial gland (Pearson's correlation test: $r=0.325, n=43, P=$ 0.033; Fig. 3). Sample size was too low to include 
Table 1. Pearson's correlation tests showing the relationships between the number of feather mites and different reproductive parameters in male and female Great Tits in central Spain. For clutch size and fledging success the $r$-statistic corresponds to that of the Spearman's rank correlation test $\left(r_{\mathrm{s}}\right)$ because normality assumptions were not fulfilled even after transformation.

\begin{tabular}{|c|c|c|c|c|c|c|}
\hline & \multicolumn{3}{|c|}{ Males } & \multicolumn{3}{|c|}{ Females } \\
\hline & $r$ & $P$ & $n$ & $r$ & $P$ & $n$ \\
\hline Laying date & -0.147 & 0.548 & 19 & 0.131 & 0.553 & 23 \\
\hline Clutch size & -0.399 & 0.091 & 19 & 0.124 & 0.574 & 23 \\
\hline Incubation period (days) & -0.111 & 0.650 & 19 & -0.022 & 0.922 & 23 \\
\hline Hatching success $(\%)$ & -0.614 & 0.009 & 17 & 0.100 & 0.675 & 20 \\
\hline Fledging success (\%) & 0.408 & 0.167 & 13 & 0.218 & 0.418 & 16 \\
\hline Breeding success (\%) & -0.647 & 0.017 & 13 & 0.333 & 0.207 & 16 \\
\hline Fledgling mass $(\mathrm{g})$ & 0.093 & 0.762 & 13 & 0.297 & 0.264 & 16 \\
\hline
\end{tabular}

sex, age and wing length as independent variables in a multivariate model, but univariate tests indicated that there was no sex ( $t$-test: $\left.t_{41}=0.51, P=0.614\right)$ or age $\left(t_{40}=1.40, P=0.169\right)$ effect on the number of feather mites. The size of the gland did not differ between sexes ( $t$-test: $t_{41}=0.25, P=0.807$ ), but varied between age classes, yearling birds having larger glands (yearlings: $129.09 \pm 28.86 \mathrm{~mm}^{3}$, adults: $\left.105.70 \pm 21.59 \mathrm{~mm}^{3} ; t_{40}=2.70, P=0.01\right)$. A relationship between feather mite abundance and wing length was not found (Pearson's correlation test: $r=-0.091, n=43, P=0.561)$. The number of mites on males did not correlate with that of their mates (Pearson's correlation test: $r=0.365, n=19, P=0.125$ ).

A multiple regression model showed that the number of feather mites depended on the size of the uropygial gland even when controlling for the hour of capture (model, $F_{2,40}=4.713, P=0.015, r^{2}=0.15$; hour of capture, $\beta_{40}=0.292, P=0.047$; uropygial gland size, $\beta_{40}=0.307, P=0.037$ ), as predicted given that the hour of capture did not correlate with uropygial gland size (see Study area and methods).

\section{Reproductive parameters}

When the number of feather mites in males was analysed taking into account the different reproductive parameters, a negative relationship was found with hatching success and breeding success (Table 1, Fig. 4). However, significant relationships were not found between the number of feather mites in females and any reproductive parameter (Table 1 ).

\section{Plumage colour}

The spectral analyses of the yellow breast of Great Tits showed that the scores of the second axis
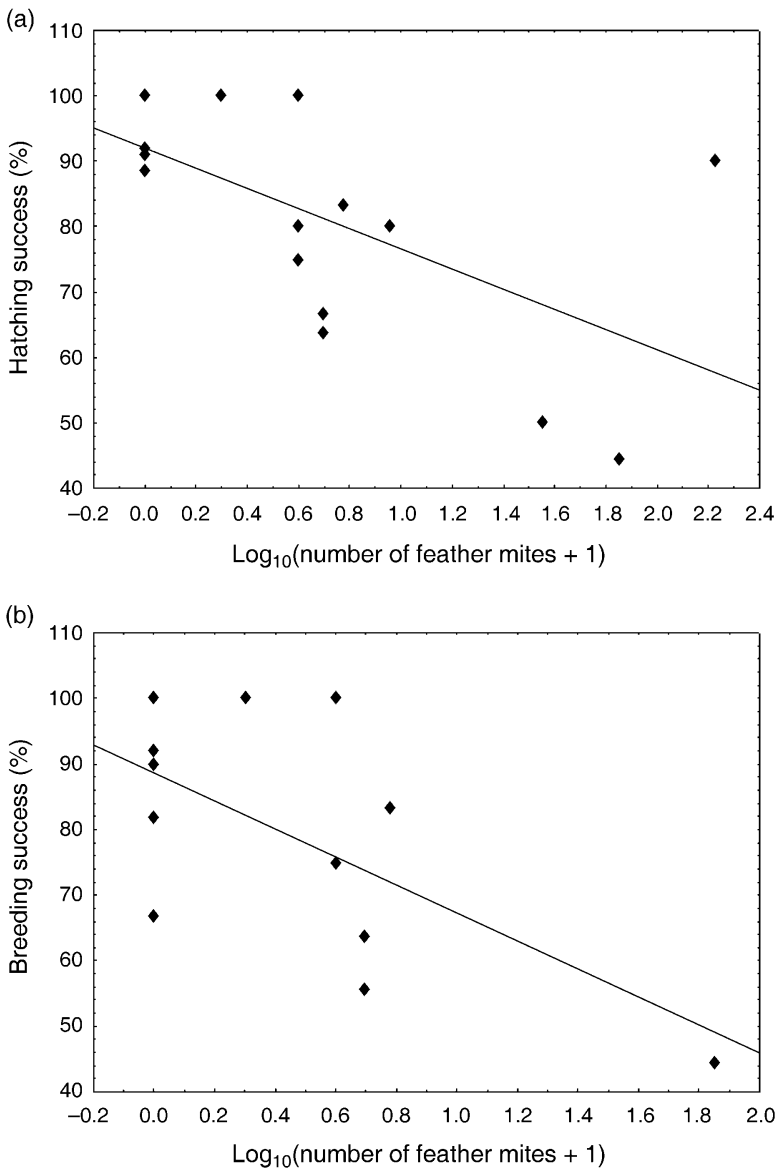

Figure 4. Relationship between the number of feather mites and hatching (a) and breeding success (b) of male Great Tits.

segregated by the PCA were negatively correlated with the number of feather mites (Pearson's correlation test: $r=-0.580, n=17, P=0.015$; Fig. 5). Thus, birds with yellower breasts had higher mite loads. In spite of the relationship found between the number 


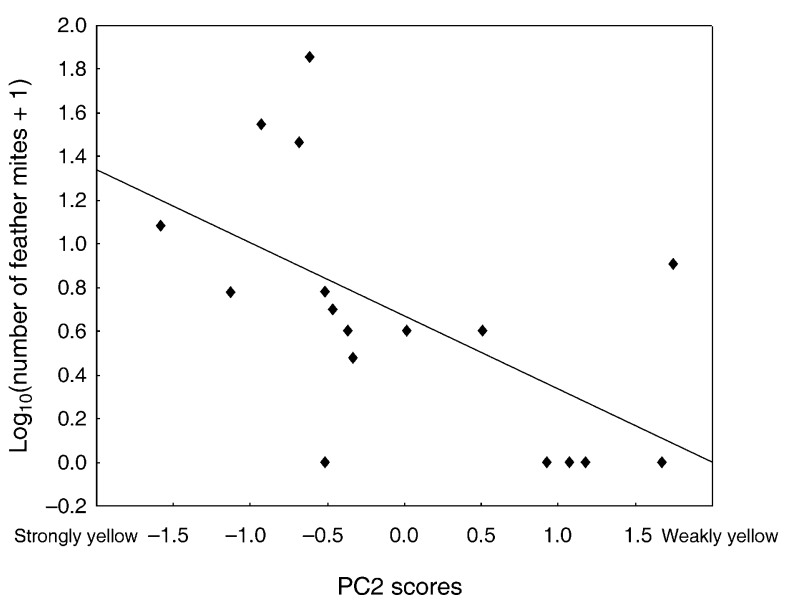

Figure 5. Relationship between the number of feather mites and the scores of the second axis segregated by the PCA, denoting higher mite loads in Great Tits with more saturated yellow feathers.

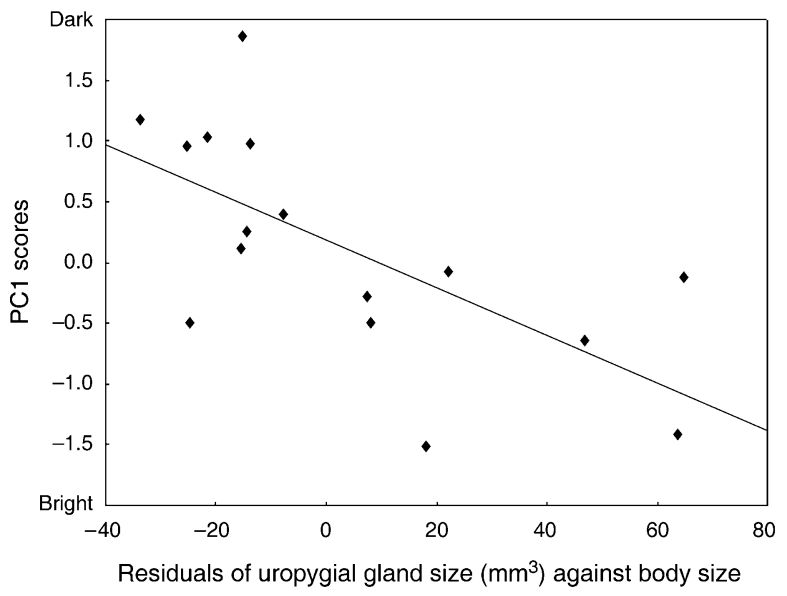

Figure 6. Relationship between the size of the uropygial gland and the scores of the first axis segregated by the PCA, denoting brighter plumages in Great Tits with larger glands.

of feather mites and hatching and breeding success, these parameters did not correlate with PC2 in either males (Spearman's correlation test: hatching success, $r_{\mathrm{s}}=0.75, n=7, P=0.052$; breeding success, $r_{\mathrm{s}}=0.60$, $n=6, P=0.208$ ) or females (hatching success, $r_{\mathrm{s}}=$ $0.25, n=7, P=0.585$; breeding success, $r_{\mathrm{s}}=0.23$, $n=6, P=0.658$ ), although these results must be interpreted with caution owing to the small sample sizes. The relationship between $\mathrm{PCl}$ scores (achromatic brightness) and uropygial gland size was significant, indicating that larger glands correspond to brighter plumages (Pearson's correlation test: $r=-0.661$, $n=16, P=0.005$; Fig. 6 ). $\mathrm{PCl}$ was not related to feather mite abundance (Pearson's correlation test: $r=-0.148, n=17, P=0.571$ ). It was not possible to obtain significant models from ANCOVAs including the sex of the birds as a fixed factor, but Student's $t$-tests did not reveal sex differences in the scores of the axes (PCl: $t_{15}=0.74, P=0.470 ; \mathrm{PC} 2: t_{15}=1.35$, $P=0.196)$.

\section{DISCUSSION}

Various authors have suggested that feather mites benefit from the host's production of uropygial oil upon which they feed (Blanco et al. 1997, 1999, Jovani \& Blanco 2000, Blanco \& Frías 2001), and Dubinin (1951) explicitly hypothesized that larger uropygial glands are responsible for higher mite loads for this reason. However, this hypothesis had not been tested previously. The results of the present study show for the first time that feather mite abundance increases with the size of the uropygial gland of their hosts, in agreement with the proposal of the above authors. This may have important implications for the study of bird-mite interactions, as mites may depend, at least in part, on the uropygial secretions of their hosts to survive. For example, if birds living in aquatic environments need larger uropygial glands in order better to waterproof their plumage than terrestrial birds, it could be predicted that higher mite loads should be harboured by members of those species. Indeed, the higher mite loads reported by Dubinin (1951) corresponded to sandpipers, waterfowl and the Osprey Pandion haliaetus, species with well-developed uropygial glands. Thus, if feather mites have any effect on the hosts' fitness (i.e. are not neutral symbionts), interspecific variations in some life-history traits could be explained partly by variance in the size of the uropygial gland.

It is widely accepted that the intensity (and other colour components) of carotenoid-based plumages is an honest indicator of health and quality (reviewed in Senar 2004). Recent studies show that hue and chroma (i.e. saturation) are the colour parameters which are related to the carotenoid content of plumage (Saks et al. 2003, McGraw \& Gregory 2004), and thus are the components which should be related to health and condition in studies of this type of plumage coloration. Because the number of feather mites is positively correlated with the chromaticity of the yellow breast of Great Tits, these mites seem to be related to birds in prime condition, whereas the contrary should have been found if feather mites were parasitic (Proctor \& Owens 2000). 
However, this study is entirely correlational and the contrary could also be true. Thus, if feather mites benefit from uropygial gland secretions, higher mite loads could be found in yellower (i.e. healthier) Great Tits just because these birds are able to secrete greater volumes of oil.

Regardless, the results found here are not in agreement with the previous findings of Thompson et al. (1997), Blanco et al. (1999), Harper (1999) and Figuerola et al. (2003), who either associated higher feather mite loads with duller and less saturated plumages or reported no association between mites and plumage colour. However, these studies suffer from some methodological problems, which should be taken into account. First, colour measurements are based on human standards and thus are not an objective approach to plumage colour. By contrast, Figuerola et al. (2003) showed that feather mite loads decrease while plumage brightness and chroma increase in Serins Serinus serinus after the application of an insecticide. However, the insecticide was not specific for feather mites, so other pathogenic ectosymbionts could have caused variations in plumage colour (Figuerola et al. 2003). Furthermore, it has been found that feather mites can be associated with avian pox, and true ectoparasites (Thompson et al. 1997, Pérez-Tris et al. 2002, Lindström et al. 2004) and endoparasites (Hill 1999) are more likely to have detrimental effects on plumage (Dowling et al. 2001b). Although the contrary (i.e. that the positive relationship found here between feather mite load and plumage yellowness is caused by those pathogenic ectosymbionts) is also possible, it should be considered improbable, as intensive coloration is associated with birds free of pathogens (for a review see Senar 2004). Figuerola et al. (2003) also found daily and seasonal variations in feather mite abundance and plumage coloration, and suggested that these are the causes of the failure by Blanco et al. (1999) to detect a relationship between feather mites and coloration. In the present study the relationship between the number of feather mites and the hour of capture was not significant, and the sampling period ( $<2$ months) was much shorter than that reported by Figuerola et al. (2003, 9 months), so that possible daily and seasonal variations in plumage colour are not likely to explain the results found here. By contrast, the negative effect of feather mites on their hosts found by Harper (1999) should be treated with caution because he only considered feather mites harboured by primary wing feathers, thus ignoring the feathers in which the majority of mites are found in passerines (see below). Thus, further work is needed to obtain clear relationships between feather mite load and plumage colour.

Results apparently contrary to those obtained from plumage colour were found when the number of feather mites was related to different reproductive parameters; a negative correlation between feather mite load and hatching and breeding success could be documented for male but not female Great Tits. Because parasites have a detrimental effect on the breeding performance of their hosts (e.g. Merino et al. 2000, Proctor \& Owens 2000, Sanz et al. 2001), these results probably agree with the idea that feather mites form parasitic associations. However, incubation and brooding in the Great Tit is exclusively carried out by the female (Gosler 1993, Sanz \& Tinbergen 1999), which makes it necessary to treat these results with caution. Moreover, Mironov (2000) and Mironov and Malyshev (2002) found that the mite load of female Chaffinches Fringilla coelebs decreased abruptly during the nesting period because feather mites migrate from the females onto the nestlings during the night. This makes it possible for mite load to have a negative relationship to fledging success in a parent bird without implying that mites are parasitic, as a higher number of fledglings could imply a lower number of mites, not vice versa. Because all the correlations found in this observational study could not reflect causal relationships, experimental removal of feather mites is needed to determine the nature of these mite-bird associations (Figuerola et al. 2003, Proctor 2003).

Blanco et al. (1999) found higher mite loads on male than on female Linnets and argued that this could be due to higher volumes of uropygial oil secreted by males as a consequence of their higher androgen levels. Sex differences in feather mite load were not detected here, but neither were those differences found in uropygial gland size, which could indicate that both sexes harboured similar mite loads. However, Dowling et al. (2001b) observed that male Seychelles Warblers devoted more time to preening than did females, but without finding sex differences in mite loads. Thus, differences in androgen levels (Jacob \& Ziswiler 1982) may not be enough to account for variation between sexes in feather mite abundance. Indeed, other studies have failed to find sex differences in mite loads (Blanco et al. 1997, Blanco \& Frías 2001, Pérez-Tris et al. 2002).

There was no effect of age on the number of feather mites, although Blanco et al. (1997) and Blanco and Frías (2001) found an increase in mite load with 
increasing age of the birds. However, that increase was also associated with an increase in the birds' sociability, a factor that seems compelling in explaining variation in mite abundance and prevalence at both interspecific (Poulin 1991, Figuerola 2000) and intraspecific levels (Blanco et al. 1997, Jovani \& Blanco 2000, Blanco \& Frías 2001), and the number of feather mites of males did not correlate with that of their mates in the present study, contrary to the findings of Blanco et al. (1997). It is probable that post-breeding and/or winter sociality are more important factors enhancing mite acquisition in birds than mate contact during the breeding period in territorial species as here, because a higher number of contacts occurs in wintering groups, thus enhancing mite transference (Lindström et al. 2004). In agreement with this, Blanco et al. (1997) found a decrease in mite abundance when the birds came into breeding condition. By contrast, yearling Great Tits had larger glands than adults. However, despite the fact that Dowling et al. (2001a) suggested that young Seychelles Warblers had higher mite loads because they produced more uropygial oil, no age effect was found in the number of feather mites in the Great Tits. This requires further investigation.

With regard to the location of mites on the wing feathers, most were found on secondaries. This tendency of feather mites to be distributed on the central feathers of the wing has been reported for other passerines by Jovani and Serrano $(2001,2004)$, and the cause seems to be that mites are better at escaping from moulting feathers when they are located in central rather than in more distal positions (Jovani \& Serrano 2001).

By contrast, it has been proposed that the secretions of the uropygial gland could act as a cosmetic by increasing plumage brightness, and thus feathers coated with more uropygial oil would look glossier (Andersson \& Amundsen 1996, Blanco et al. 1999). Figuerola and Senar (2005) have also speculated that the oil production by the uropygial gland is responsible for changes in plumage colour. In this case, a positive correlation between plumage brightness measured through $\mathrm{PCl}$ scores and uropygial gland size was found, indicating that greater volumes of oil increase the amount of achromatic reflectance. It is known that uropygial gland secretions can create special colorations that act as cosmetics in some species (Andersson \& Amundsen 1996, Blanco et al. 1999), but this is the first time that an objective measure of plumage brightness has been related to the size of the uropygial gland. This result suggests a novel source for the study of colour signals, and indicates that the size of the uropygial gland should be taken into account in studies of plumage coloration. As brightness does not reflect the carotenoid content of plumage, at least in Greenfinches Carduelis chloris (Saks et al. 2003) and American Goldfinches Carduelis tristis (McGraw \& Gregory 2004), it is not likely to reflect the health or condition of the birds. Thus, the evolutionary logic behind cosmetic brightness should be investigated if future studies relate this to mate choice. For example, it could be speculated that cosmetic brightness acts as an amplifier (Hasson 1989) of the other colour parameters, increasing the perceptibility of health and condition.

We thank Roger Jovani for early discussions on the relationship between feather mites and uropygial gland size and Juan A. Amat for suggestions for measuring the uropygial gland. Heather Proctor (University of Alberta) provided a list of records of mites found on Great Tits and interesting literature. The manuscript was greatly improved by the comments of Juan Moreno, Heather Proctor and an anonymous reviewer. Financial support was obtained from the project CGL2004-00787 of the Spanish Ministerio de Educación y Ciencia, and I.G. benefited from an FPI grant from the same ministry and the European Social Fund.

\section{REFERENCES}

Andersson, S. \& Amundsen, T. 1996. Ultraviolet colour vision and ornamentation in bluethroats. Proc. R. Soc. Lond. B 264: 1587-1591.

Atyeo, W.T. \& Braasch, L. 1966. The feather mite genus Proctophyllodes (Sarcoptiformes: Proctophyllodidae). Bull. Univ. Nebr. State Mus. 5: 1-354.

Behnke, J.M., McGregor, P.K., Shepherd, M., Wiles, R., Barnard, C., Gilbert, F.S. \& Hurst, J.L. 1995. Identity, prevalence and intensity of infestation with wing feather mites on birds (Passeriformes) from the Setubal Peninsula of Portugal. Exp. Appl. Acarol. 19: 443-458.

Bennett, A.T.D., Cuthill, I.C. \& Norris, K.J. 1994. Sexual selection and the mismeasure of color. Am. Nat. 144: 848-860.

Blanco, G. \& Frías, O. 2001. Symbiotic feather mites synchronize dispersal and population growth with host sociality and migratory disposition. Ecography 24: 113-120.

Blanco, G., Seoane, J. \& de la Puente, J. 1999. Showiness, non-parasitic symbionts, and nutritional condition in a passerine bird. Ann. Zool. Fenn. 36: 83-91.

Blanco, G., Tella, J.L. \& Potti, J. 1997. Feather mites on groupliving Red-billed Choughs: a non-parasitic interaction? J. Avian Biol. 28: 197-206.

Blanco, G., Tella, J.L., Potti, J. \& Baz, A. 2001. Feather mites on birds: costs of parasitism or conditional outcomes? J. Avian Biol. 32: 271-274.

Cerny, V. 1964. Contribution to the knowledge of feather mites (Analgesoidea) from Czechoslovakia II. Cesk. Parasitol. 11: 65-69. 
Cerny, V. 1971. Zur Kenntnis der Federmilben (Arach., Acar.) von schweizerischen Vögeln. Mitt. Schweiz. Entomol. Ges. 44: $285-298$.

Cherry, M.I. \& Bennett, A.T.D. 2001. Egg colour matching in an African cuckoo, as revealed by ultraviolet-visible reflectance spectrophotometry. Proc. R. Soc. Lond. B 268: 565-571.

Clayton, D.H. \& Tompkins, D.M. 1995. Comparative effects of mites and lice on the reproductive success of rock doves (Columba livia). Parasitology 110: 195-206.

Cuthill, I.C., Bennett, A.T.D., Partridge, J.C. \& Maier, E.J. 1999. Plumage reflectance and the objective assessment of avian sexual dichromatism. Am. Nat. 153: 183-200.

Cuthill, I.C., Partridge, J.C., Bennett, A.T.D., Church, S.C., Hart, N.S. \& Hunt, S. 2000. Ultraviolet vision in birds. Adv. Stud. Behav. 29: 159-214.

Dowling, D.K., Richardson, D.S., Blaakmeer, K. \& Komdeur, J. 2001a. Feather mite loads influenced by salt exposure, age and reproductive stage in the Seychelles Warbler Acrocephalus sechellensis. J. Avian Biol. 32: 364-369.

Dowling, D.K., Richardson, D.S. \& Komdeur, J. 2001b. No effects of a feather mite on body condition, survivorship, or grooming behavior in the Seychelles warbler, Acrocephalus sechellensis. Behav. Ecol. Sociobiol. 50: 257-262.

Dubinin, V.B. 1951. Feather mites (Analgesoidea). Part I. Introduction to their study. Fauna USSR 6: 1-363 (in Russian).

Elder, W.H. 1954. The oil gland of birds. Wilson Bull. 66: 6-31.

Figuerola, J. 2000. Ecological correlates of feather mite prevalence in passerines. J. Avian Biol. 31: 489-494.

Figuerola, J., Domènech, J. \& Senar, J.C. 2003. Plumage colour is related to ectosymbiont load during moult in the serin, Serinus serinus: an experimental study. Anim. Behav. 65: 551-557.

Figuerola, J. \& Senar, J.C. 2005. Seasonal changes in carotenoidand melanin-based plumage coloration in the Great Tit. Ibis 147: 797-802.

Gosler, A.G. 1993. The Great Tit. London: Hamlyn.

Gosler, A.G., Greenwood, J.J.D., Baker, J.K. \& Davidson, N. 1998. Biometric determination of body size and condition in passerines: a report to the British Ringing Committee. Bird Study 45: 92-103.

Hamilton, W.D. \& Zuk, M. 1982. Heritable true fitness and bright birds: a role for parasites? Science 218: $384-386$.

Harper, D.G.C. 1999. Feather mites, pectoral muscle condition, wing length and plumage coloration of passerines. Anim. Behav. 58: 553-562.

Hasson, O. 1989. Amplifiers and the handicap principle in sexual selection: a different emphasis. Proc. R. Soc. Lond. B 235: 383-406.

Hill, G.E. 1999. Mate choice, mate quality, and carotenoid-based plumage coloration. Proc. Int. Ornithol. Congr. 22: 1654-1668.

Hunt, S., Bennett, A.T.D., Cuthill, I.C. \& Griffiths, R. 1998. Blue tits are ultraviolet tits. Proc. R. Soc. Lond. B 265: 451-455.

Jablonska, J. 1986. Specificity of some mite species of the superfamily Analgesoidea to bird hosts in the Warsaw Zoo. Acta Parasitol. Pol. 15: 55-62.

Jacob, J. \& Ziswiler, V. 1982. The uropygial gland. In Farner, D.S., King, J.R. \& Parkes, K.C. (eds) Avian Biology, Vol. 4: 199-324. New York: Academic Press.

Jenni, L. \& Winkler, R. 1994. Moult and Ageing of European Passerines. London: Academic Press.

Johnsen, A., Delhey, K., Andersson, S. \& Kempenaers, B. 2003. Plumage colour in nestling blue tits: sexual dichromatism, condition dependence and genetic effects. Proc. R. Soc. Lond B 270: 1263-1270.

Jovani, R. \& Blanco, G. 2000. Resemblance within flocks and individual differences in feather mite abundance on long-tailed tits, Aegithalos caudatus (L.). Écoscience 7: 428-432.

Jovani, R. \& Serrano, D. 2001. Feather mites (Astigmata) avoid moulting wing feathers of passerine birds. Anim. Behav. 62: 723-727.

Jovani, R. \& Serrano, D. 2004. Fine-tuned distribution of feather mites (Astigmata) on the wing of birds: the case of Blackcaps Sylvia atricapilla. J. Avian Biol. 35: 16-20.

Lindström, K.M., Foufopoulos, J., Pärn, H. \& Wikelski, M. 2004. Immunological investments reflect parasite abundance in island populations of Darwin's finches. Proc. R. Soc. Lond. B 271: 1513-1519.

Mays, H.L. Jr, McGraw, K.J., Ritchison, G., Cooper, S., Rush, V. \& Parker, R.S. 2004. Sexual dichromatism in the Yellowbreasted Chat Icteria virens: spectrophotometric analysis and biochemical basis. J. Avian Biol. 35: 125-134.

McGraw, K.J. \& Gregory, A.J. 2004. Carotenoid pigments in male American goldfinches: what is the optimal biochemical strategy for becoming colourful? Biol. J. Linn. Soc. 83: 273280.

Mennill, D., Doucet, S.M., Montgomerie, R. \& Ratcliffe, L.M. 2003. Achromatic color variation in black-capped chickadees, Poecile atricapilla: black and white signals of sex and rank. Behav. Ecol. Sociobiol. 53: 350-357.

Merino, S., Moreno, J., Sanz, J.J. \& Arriero, E. 2000. Are avian blood parasites pathogenic in the wild? A medication experiment in blue tits (Parus caeruleus). Proc. R. Soc. Lond. B 267: 2507-2510.

Mironov, S.V. 1996. Feather mites from passerines of the northwest of Russia. Parasitologiya 30: 521-539 (in Russian).

Mironov, S.V. 1997. Contribution to the feather mites of Switzerland with descriptions of five new species (Acarina: Sarcoptiformes). Bull. Soc. Entomol. Suisse 40: 455-471.

Mironov, S.V. 2000. Seasonal dynamics of the feather mite Monojoubertia microphylla (Astigmata: Analgoidea: Proctophyllodidae) on the Chaffinch Fringilla coelebs. Parasitologiya 34: 457-469 (in Russian).

Mironov, S.V. \& Malyshev, L.L. 2002. Dynamics of infection of Chaffinch nestlings Fringilla coelebs with feather mites (Acari: Analgoidea). Parasitologiya 36: 356-374 (in Russian).

Moreno, J., Morales, J., Lobato, E., Merino, S., Tomás, G. \& Martínez-de la Puente, J. 2005. Evidence for the signaling function of egg color in the pied flycatcher Ficedula hypoleuca. Behav. Ecol. 16: 931-937.

Nattress, B. 1995. Some records of feather mites (Acari: Astigmata) in Yorkshire. Naturalist 101: 31-32.

Pérez-Tris, J., Carbonell, R. \& Tellería, J.L. 2002. Parasites and the blackcap's tail: implications for the evolution of feather ornaments. Biol. J. Linn. Soc. 76: 481-492.

Poulin, R. 1991. Group-living and infestation by ectoparasites in passerines. Condor 93: 418-423.

Proctor, H. 2003. Feather mites (Acari: Astigmata): ecology, behavior and evolution. Annu. Rev. Entomol. 48: 185-209.

Proctor, H. \& Owens, I. 2000. Mites and birds: diversity, parasitism and coevolution. Trends Ecol. Evol. 15: 358-364.

Saino, N., Møller, A.P. \& Bolzern, M. 1995. Testosterone effects on the immune system and parasite infestations in the barn swallow (Hirundo rustica): an experimental test of the immunocompetence hypothesis. Behav. Ecol. 6: 397-404. 
Saks, L., McGraw, K. \& Hõrak, P. 2003. How feather colour reflects its carotenoid content. Funct. Ecol. 17: 555-561.

Sanz, J.J., Arriero, E., Moreno, J. \& Merino, S. 2001. Female hematozoan infection reduces hatching success but not fledging success in Pied Flycatchers Ficedula hypoleuca. Auk 118: 750-755.

Sanz, J.J. \& Tinbergen, J.M. 1999. Energy expenditure, nestling age, and brood size: an experimental study of parental behavior in the great tit Parus major. Behav. Ecol. 10: 598606.

Senar, J.C. 2004. Mucho más que plumas. Barcelona: Monografies del Museu de Ciències Naturals, 2.

Shawkey, M.D. \& Hill, G.E. 2005. Carotenoids need structural colours to shine. Biol. Lett. 1: 121-124.
Svensson, L. 1992. Identification Guide to European Passerines. Stockholm: Fingraf AB.

Thompson, C.W., Hillgarth, N., Leu, M. \& McClure, H.E. 1997. High parasite load in house finches (Carpodacus mexicanus) is correlated with reduced expression of a sexually selected trait. Am. Nat. 149: 270-294.

Wiles, P.R., Cameron, J., Behnke, J.M., Hartley, I.R., Gilbert, F.S. \& McGregor, P.K. 2000. Season and ambient air temperature influence the distribution of mites (Proctophyllodes stylifer) across the wings of blue tits (Parus caeruleus). Can. J. Zool. 78: 1397-1407.

Received 10 November 2005; revision accepted 28 March 2006. 